\title{
Estimation of R\&D capital stock in China's high-tech industry
}

\author{
Yan Zou ${ }^{a}$, Lingjie Meng ${ }^{a^{*}}$ \\ ${ }^{a}$ Nanjing University of Science and Technology, School of Economics and Management, \\ China \\ *Corresponding author: Lingjie Meng, Professor, mlj339@aliyun.com
}

\begin{abstract}
$R \& D$ capital stock is often used in the study of high-tech industry, but there are some deficiencies in the existing methods of measuring R\&D capital stock. Based on the existing literature, a new method to estimate R\&D capital stock is proposed in this paper. We measure the R\&D capital stock of 17 industry segments in China's high-tech industry from 2009 to 2015 by this new method and compare the results with the ones calculated by previous methods. It turned out that different measurement ideas and parameter settings have a great influence on the measurement results.
\end{abstract}

Key words: high-tech industry; $R \& D$ expenses; capital stock; perpetual inventory method; depreciation rate; price index

\section{Introduction}

R\&D capital investment is closely related to the development of high-tech industry. Many scholars have studied high-tech industry from various perspectives, mostly involving the R\&D capital. Because of the inadequate statistics and non-standard accounting methods of R\&D capital investment in China, different measurements will affect the results in different degrees. Under this background, we want to know how much R\&D measurements contribute to the high-tech industry and how does the $R \& D$ investment guide the further development of the high-tech industry. In order to answer these questions and improve the rationality and scientificity of the research, we estimate the R\&D capital stock scientifically.

The representative studies of the capital stock in China are as follows: Zhang et al. $(2004)^{1}$ measure 30 provinces physical capital stock from 1992 to 2000 by perpetual inventory method. $W u(2006)^{2}$, a pioneer of the calculating R\&D capital stock in China, measure the R\&D capital stock of China's industrial sectors. Liu et al. (2015) ${ }^{3}$, Jiang and Sun $(2016)^{4}$, measure China's R\&D capital stock successively. The calculation of R\&D capital stock in high-tech industry only appears in related research. Zhu and $\mathrm{Xu}(2006)^{5}$, Liu and 
Zhang (2013) ${ }^{6}$, Chen et al. (2014) ${ }^{7}$ study the technical innovation efficiency of China's high-tech industry based on the R\&D capital stock. There are still some shortcomings, such as R\&D capital stock that is directly represented by the expenses flow of science and technology activities or without considering the influence of $R \& D$ external expenses. Otherwise, the selection of R\&D capital consumption rate is usually unreasonable. We comprehensively consider the composition of R\&D capital of high-tech industry and select the appropriate index to estimate the R\&D capital stock of China's high-tech industry in this paper. The results may make some contributions to the research on the innovation ability and technical efficiency of high-tech industry.

\section{Estimation method and variable selection}

\subsection{Estimation method of $R \& D$ capital stock}

The different assumptions and basis in perpetual inventory method influence the results of R\&D capital stock measurement. Existing studies are classified according to the selected key parameters in Table 1

Table 1 - Classification the study of R\&D capital stock estimates

\begin{tabular}{|l|c|c|}
\hline Author & R\&D capital increment & Depreciation rate \\
\hline Z.Youwei, X.Kangning (2006) & Expenses on science and technology activities & $15 \%$ \\
\hline $\begin{array}{l}\text { J.Tongtong (2012), D.Jin (2007) } \\
\text { F.Linjun et al. (2010) }\end{array}$ & $\begin{array}{c}\text { Expenses on science and technology activities } \\
\text { exclude R\&D staff's salary costs }\end{array}$ & $15 \%$ \\
\hline $\begin{array}{l}\text { Z.Wenji (2011), C.Jianli et al.(2014) } \\
\text { L.Zhiying et al.(2013) }\end{array}$ & R\&D internal expenses \\
\hline W.Yanbin (2006), W.Jun (2009) & R\&D expenses minus R\&D staff's salary costs & $15 \%$ \\
\hline J.Yonghong, S.Fenge (2016) & R\&D capital formation & W.Jun: 9\%-17.5\% \\
\hline
\end{tabular}

R\&D expenses include internal and external expenses. The former is divided into daily and capital expenses. As daily expenses and raw material costs of internal expenses are all transferred to the product in the R\&D period, so the current investment can only form the current R\&D capital stock. Generally, the daily expenses should exclude the R\&D staff's salary costs in order to avoid the duplication. However, due to the limitation of data resources to acquire the share of personnel expenditure accounting for R\&D internal expenses, the daily expenses are usually regarded as the current capital stock. Differently, the fixed capital's value is gradually transferred into the products, playing a role not only in the current production but 
also the future $R \& D$ innovation process. As for $R \& D$ external expenses, it refers to the payment to domestic and foreign research institutions, universities and enterprises for achieve the $R \& D$ goal, which should be included in the $R \& D$ capital stock, and we assume that $R \& D$ external expenses all form the capital stock in the current period.

Based on the above analysis, we construct a new method to estimate the R\&D capital stock in high-tech industry :

$$
R_{t}=K_{t}+N_{t}+W_{t}
$$

Where $R_{t}$ denotes $\mathrm{R} \& \mathrm{D}$ capital stock in period $\mathrm{t}, K_{t}$ denotes the accumulation of instrument and equipment stock of R\&D internal expenses in period t, $N_{t}$ and $W_{t}$ respectively express the $R \& D$ internal expenses exclude instrument and equipment costs and the $R \& D$ external expenses in period t (constant price).

\subsection{Estimation basis and index selection}

\subsubsection{Estimation of instrument and equipment stock}

Griffhes $(1980,1986,1998)^{8-10}$ use the perpetual inventory method to estimate R\&D capital stock. which now is commonly used by most scholars. Referring to this method, we estimate the instrument and equipment stock of R\&D internal expenses by the following basic formula:

$$
K_{t}=\sum_{t=1}^{n} u_{k} E_{t-k}+(1-\delta) K_{t-1}
$$

Where $K_{t}$ and $K_{t-1}$ denote the R\&D capital stock respectively in term t and term t-1, $\delta$ stands for $R \& D$ asset depreciation rate, $E_{t-k}$ denotes $R \& D$ expenses with constant price, $k$ is lag phase, $u_{k}$ is the lag discount factor of $E_{t-k}$. Referring to the practice of most scholars, we assume that $u_{k}=1$ and $k=1$, here $K_{t}$ is defined as:

$$
K_{t}=E_{t-1}+(1-\delta) K_{t-1}
$$

By definition (3), the prerequisite for measuring the stock of period $t$ is to acquire the data as follows: base stock of the instrument and equipment, the current expenses, the price index and the depreciation rate.

Firstly, determine the stock of the instrument and equipment. Here we select the instrument and equipment expenses included in the R\&D internal expense as E according to China High 
Technology Industry Statistical Yearbook from 2010-2016 (2009 is the base year). Secondly, replace the price index with the equipment and instrument purchase price index. Thirdly, determine the depreciation rate of the instrument and equipment stock. On the ground of the existing literature, the depreciation rate of the R\&D capital stock is usually set as $15 \%$ in accordance with the empirical rule, ignoring the rapid changes in the high-tech industry and great influence on changes of assets value caused by technology advances and emergence of new alternatives. Finland ${ }^{11}$ set $R \& D$ assets depreciation rate at $10 \%-30 \%$ according to different industries, and the depreciation rate of communications equipment industry is $20 \%$. Compared with developed countries, the technology level of China's high-tech industry is relatively lower and the period of $R \& D$ asset is shorter. Thus, the depreciation rate is set as $25 \%$ in this paper after the comprehensive consideration. Finally, determine the base stock. We assume that the average growth rate of stock equals to that of the instrument and equipment expenses with the reference to the practice of $W u(2006)^{1}$, the base stock is:

$$
K_{0}=E_{0} / g+\delta
$$

Where, $g$ is the arithmetic average growth rate of the instrument and equipment expenses during the inspection period. After calculating the base stock, according to the formula (3), we can calculate the instruments and equipment stock of 17 sub-industries of the high-tech industry every year.

\subsubsection{The price index selection of the current expenses}

Since the unified R\&D asset price index do not exist at home and abroad now, we need to construct an appropriate price index according to the calculation category. Generally, it is replaced by a relative price index or a weighted average of a series of indices. The practice of Zhu and $X u(2006)^{5}$, using the Consumer Price Index (CPI) and the Producer Price Index (PPI) to construct the R\&D price index, which is the model for this paper. As the proportion of personnel expenses in R\&D expenses is 0.36 on average, we set the CPI and PPI as 0.64 and 0.36 respectively. In addition, due to $R \& D$ external expenses are in the form of cash , we use purchase price index for its price reduction.

\section{Estimation results and analysis of $R \& D$ capital stock}

From table 1, the R\&D capital stock of high-tech industries increase steadily except the computer external equipment manufacturing. Especially, the average growth rate of $R \& D$ capital stock in the electronics device manufacturing industry reaches $25.3 \%$ these years. 
Table 2 - R\&D capital stock of high - tech industry 17 sub-sectors from 2009-2015 (unit: billion yuan)

\begin{tabular}{|l|c|c|c|c|c|c|c|}
\hline Industry & 2009 & 2010 & 2011 & 2012 & 2013 & 2014 & 2015 \\
\hline Chemicals manufacturing & 9.0 & 9.4 & 12.6 & 19.0 & 22.2 & 22.7 & 26.4 \\
\hline Proprietary Chinese medicine manufacturing & 3.4 & 3.0 & 4.4 & 7.3 & 8.2 & 8.3 & 9.0 \\
\hline Bio-pharmaceutical manufacturing & 2.1 & 1.7 & 3.2 & 5.0 & 6.1 & 6.9 & 8.1 \\
\hline Aircraft manufacturing and repair & 5.3 & 7.9 & 12.1 & 13.1 & 14.4 & 15.4 & 14.6 \\
\hline Spacecraft manufacturing & 1.4 & 0.7 & 1.6 & 2.1 & 2.2 & 2.5 & 2.1 \\
\hline Communications equipment manufacturing & 28.1 & 30.7 & 37.7 & 52.2 & 55.6 & 59.8 & 72.3 \\
\hline Radar and ancillary equipment manufacturing & 1.0 & 0.8 & 1.1 & 1.7 & 1.9 & 1.7 & 1.7 \\
\hline Radio and television equipment manufacturing & 0.7 & 0.6 & 1.0 & 2.7 & 2.9 & 3.1 & 4.1 \\
\hline Electronics device manufacturing & 8.7 & 9.6 & 13.6 & 21.3 & 26.4 & 28.2 & 33.7 \\
\hline Electronic component manufacturing & 9.0 & 9.3 & 12.9 & 17.5 & 20.1 & 20.2 & 24.4 \\
\hline Audio-visual equipment manufacturing & 6.5 & 6.3 & 9.8 & 11.2 & 13.4 & 13.2 & 14.6 \\
\hline Other electronic equipment manufacturing & 1.5 & 1.3 & 2.6 & 4.8 & 5.3 & 5.8 & 7.1 \\
\hline Computer manufacturing & 4.5 & 4.4 & 6.3 & 7.3 & 7.5 & 7.9 & 9.2 \\
\hline Computer external equipment manufacturing & 5.3 & 7.4 & 7.9 & 3.8 & 3.7 & 3.2 & 3.1 \\
\hline Office equipment manufacturing & 0.6 & 0.5 & 0.7 & 1.0 & 1.1 & 1.3 & 1.3 \\
\hline Medical equipment manufacturing & 2.2 & 1.7 & 2.8 & 4.6 & 5.3 & 5.0 & 7.0 \\
\hline Instrumentation manufacturing & 7.3 & 5.7 & 9.8 & 14.7 & 16.3 & 17.0 & 19.1 \\
\hline
\end{tabular}

To show the difference in the estimation method of this paper, we estimate the R\&D capital stock in the same period with the previous method. In the following figure, R2 is the R\&D capital increment estimated by the R\&D internal expenses; R3 is the R\&D capital increment estimated by the result of $R \& D$ internal expenses minus the personnel expenses; $R 1$ is the result estimated by the new method in this paper.

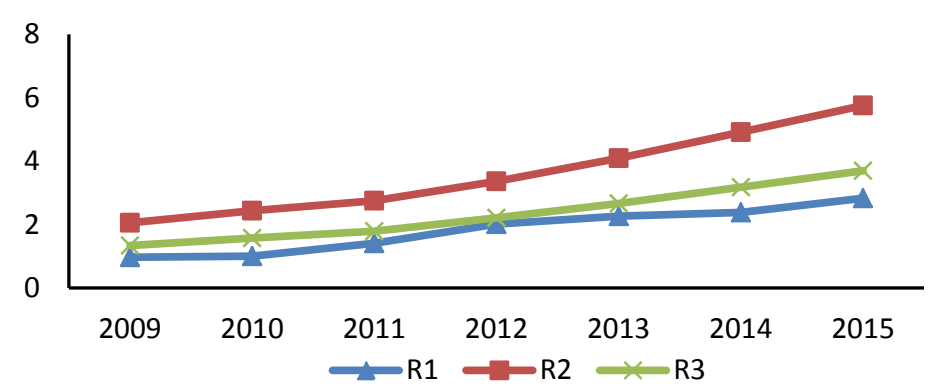

Fig.1 - Different calculation results of R\&D capital stock in high - tech industry (unit: trillion) 
As illustrated in Figure 1, R2 is much higher than R1 and R3 and the difference is increasing, mainly because that the R2's estimation method significantly overestimates the capacity of the current R\&D capital to form the later period capital stock, and its growth rate is increasing. The overall change trends of R2 and R3 are similar because the difference between them lies in whether the $R \& D$ internal expenses including personnel costs. Owing to only the instrument and equipment expenses in $\mathrm{R} 1$ affect later $\mathrm{R} \& \mathrm{D}$ capital stock but the rest of the $R \& D$ internal and external expenses only constitute the current $R \& D$ capital stock, the differences among R1, R2 and R3 are represented in not only their absolute quantities but also fluctuation trends. For the whole high-tech industry, although only R1 contains R\&D external expenditures, its stock value is lower than R2 and R3 because the R\&D capital increment of $\mathrm{R} 2$ and R3 is relatively large.

The above estimation methods have different effects on various industry segments with different characteristics of each. We only list two industry segments to illustrate due to space constraints.
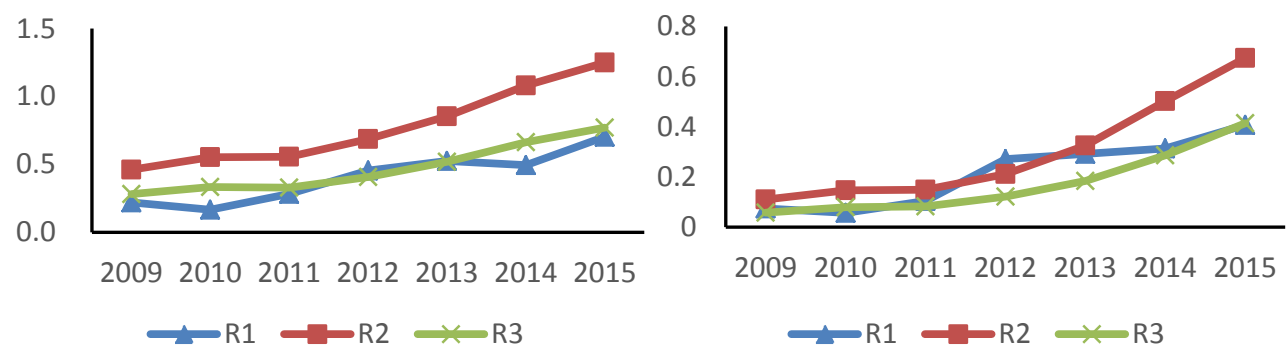

Fig.2 - Medical equipment manufacturing

Fig.3 - Radio and television equipment manufacturing Fig. 2 and 3 show that the two industry segments of the high-tech industry differ a lot in three indicators, especially between the R1 and the other two. Since the indicators significantly affect the regression analysis in the research, it is necessary to select reasonable methods and parameters to estimate R\&D capital stock in high-tech industries.

\section{Conclusion}

Based on the perpetual inventory method, we propose a new method to estimate R\&D capital stock of high-tech industry in this paper. After comparing the results with others, we conclude that different measurement ideas and parameter settings will generate a huge difference. The estimation method we propose may provide reference value for further research on innovation efficiency as well as the relationship between economic development and resource allocation in high-tech industries. However, the research data starts from 2010, which means some errors 
may exist when applying the new method in the previous years because of the different key parameters set. In order to estimate the R\&D capital stock of high-tech industry more reasonably, we put forward some suggestions, on the one hand, the $R \& D$ capital data statistics should be improved as soon as possible. On the other hand, the estimation method should be considered deeply and comprehensively according to the characteristics of certain industry.

\section{References}

1. Z.Jun et al. The Estimation of China' s provincial capital stock :1952 —2000, J. Economic Research Journal. Cssci. 10 (2004) 35-44

2. W.Yanbin, R\&D stock, knowledge function and productive efficiency, J. China Economic Quarterly. Cssci. 3 (2006) 1129-1156.

3. L.Jiancu et al. Measurements on China's R\&D capital stock, J. Research on Economic and Management. Cssci. 2 (2015) 18-25.

4. J.Yonghong, S.Fenge, The measurement of China's R\&D capital stock:1952-2014, J. The Journal of Quantitative \& Technical Economics. Cssci. 7 (2016) 112-129.

5. Z.youwei, X.Kangning, The empirical research on R\&D efficiency of Chinese high-tech industries, J.China Industrial Economy. Cssci. 11 (2006) 38-45.

6. L.Zhiying, Z.Jikun, Analysis on innovation efficiency of the different capital type enterprises in high-tech industries-Based on the three-stage DEA model, J. R\&D Management. Cssci. 3 (2013) 45-52.

7. C.Jianli et al. The research on technological innovation efficiency and its affecting factors of high-tech industry from two-stage perspective, J. Mathematics in Practice and Theory. Cscd. 4 (2014) 63-74.

8. Z. Griliches, R\&D and the productivity slowdown, J. American Economic Review. Ssci. 70 (1980) 343-348.

9. Z. Griliches, Productivity, R\&D and basic research at the firm level in the 1970's, J. American Economic Review. Ssci. 76 (1986) 141-154.

10. Z. Griliches, R\&D and Productivity, N. Chicago:University of Chicago Press. 1998.

11. URL:http://tilastokeskus.fi/tup/kantilinpito/final_report.pdf (30.7.2009.) 